\title{
A Model of Decision Support System for Choosing High School Learning Plan Using Students' O-NET Score and Multiple Intelligence
}

\author{
Thanrat Sintanakul and Charun Sanrach
}

\begin{abstract}
Choosing high school learning plan is very importance for students because if one has chosen wrong learning plan, he/she has to study in that dislike or unskilled plan for three years (until finishing high school study). In Thailand, there are many students who have chosen the wrong/dislike/unskilled learning plan. This research proposes a model of decision support system for choosing high school learning plan according to students' Ordinary National Education Test (O-NET) scores and their multiple intelligences (MI). Inputs of the proposed model are Grade 9 O-NET Scores and the results from MI Questionnaire of students. The process is consideration of the predicted Grade 12 O-NET Scores (from grade 9 O-NET scores using classification technic in data mining) together with the students' $M I$. Then, the output of the model is the list of suitable learning plan(s) for such student.
\end{abstract}

Index Terms-Decision support system, high school learning plan, multiple intelligence (MI), O-NET score.

\section{INTRODUCTION}

In Thailand, there are five main high school learning plans, i.e. Science-Math Plan, Arts-Math Plan, Language-Arts Plan, Social-Arts Plan, and General Arts Plan. There are many students who have chosen the wrong/dislike/unskilled learning plan because of several reasons, e.g. they didn't know about their talents or, sometime, they just chose their learning plans according to popularity.

There is one kind of National Education Test, in Thailand, called "O-NET", which stands for Ordinary National Education Test. O-NET is a basic national education examination for assessing knowledge and ideas of grade 6, grade 9 , and grade 12 students in accordance with 67 learning standards stated in Basic Education Core Curriculum B.E. 2551 covering 8 major subject areas - Thai, Mathematics, Science, Social Study, English, Health and Physical Education, Art, and Career and Technology. All students of grade 6,9 , and 12 have to take this examination in order to use the result as a compulsory part of their graduation and to evaluate their academic proficiency at the national level [1].

Classification is a data mining technic that maps data into

Manuscript received November 22, 2014; revised January 23, 2015. This work was supported in part by the Department of Computer Education, Faculty of Technical Education, King Mongkut's University of Technology North Bangkok, Bangkok, Thailand.

The authors are with the Department of Computer Education, Faculty of Technical Education, King Mongkut's University of Technology North Bangkok, Bangkok, Thailand (e-mail: thanrat.s@fte.kmutnb.ac.th). predefined groups or classes. It is a supervised learning method which requires labelled training data to generate rules for classifying test data into predetermined groups or classes. It is a two-phase process. The first phase is the learning phase, where the training data is analyzed and classification rules are generated. The next phase is the classification, where test data is classified into classes according to the generated rules [2].

The theory of multiple intelligences was developed in 1983 by Dr. Howard Gardner, professor of education at Harvard University. It suggests that the traditional notion of intelligence, based on I.Q. testing, is far too limited. Instead, Dr. Gardner proposes 8 different intelligences to account for a broader range of human potential in children and adults [3]. These intelligences are [4]:

- Verbal-linguistic intelligence (well-developed verbal skills and sensitivity to the sounds, meanings, and rhythms of words)

- Logical-mathematical intelligence (ability to think conceptually and abstractly, and capacity to discern logical and numerical patterns)

- Spatial-visual intelligence (capacity to think in images and pictures, to visualize accurately and abstractly)

- Bodily-kinesthetic intelligence (ability to control one's body movements and to handle objects skillfully)

- Musical intelligence (ability to produce and appreciate rhythm, pitch, and timber)

- Interpersonal intelligence (capacity to detect and respond appropriately to the moods, motivations, and desires of others)

- Intrapersonal intelligence (capacity to be self-aware and in tune with inner feelings, values, beliefs, and thinking processes)

- Naturalist intelligence (ability to recognize and categorize plants, animals, and other objects in nature)

This paper proposes the model of decision support system for choosing high school learning plan using students' O-NET scores and multiple intelligences. The model takes the Grade 9 O-NET scores and the result from MI questionnaire of students as inputs. Then processing of such inputs is divided into two steps, i.e. using classification technic of data mining to predict Grade 12 O-NET scores of students, and using the predicted scores together with students' MI to suggest appropriate learning plan(s) to students. The organization of this paper is as follows: Section II presents the research methodology. Section III shows the proposed model, which is divided into 3 parts - Input, Process, and Output of the model. And the conclusion is in Section IV. 


\section{RESEARCH MethodolOGY}

In this research, the methodology is divided into four main steps, i.e. finding the appropriated algorithm for predicting of Grade 12 O-NET score, finding the relevance between each learning plan and its emphatic subjects, finding the relevance between students' MI and suitable learning plan, and synthesizing the model.

\section{A. Finding the Appropriated Algorithm for Predicting of Grade 12 O-NET Score}

In this step, we compared 3 classification algorithms, i.e. Decision Tree, Naïve Bayes, and k-Nearest Neighbor on the O-NET Score dataset.

A Decision Tree is a tree-like graph or model. It is more like an inverted tree because it has its root at the top and it grows downwards. This representation of the data has the advantage compared with other approaches of being meaningful and easy to interpret. The goal is to create a classification model that predicts the value of a target attribute (often called class or label) based on several input attributes of the dataset [5].

A Naïve Bayes classifier is a simple probabilistic classifier based on applying Bayes' theorem (from Bayesian statistics) with strong (naive) independence assumptions. A more descriptive term for the underlying probability model would be 'independent feature model'. In simple terms, a Naïve Bayes classifier assumes that the presence (or absence) of a particular feature of a class (i.e. attribute) is unrelated to the presence (or absence) of any other feature [5].

The k-Nearest Neighbor algorithm is based on learning by analogy, that is, by comparing a given testing data with training data that are similar to it. The training data are described by $\mathrm{n}$ attributes. Each data represents a point in an n-dimensional space. In this way, all of the training data are stored in an n-dimensional pattern space. When given an unknown data, a k-nearest neighbor algorithm searches the pattern space for the $\mathrm{k}$ training data that are closest to the unknown data. These $\mathrm{k}$ training data are the $\mathrm{k}$ "nearest neighbors" of the unknown data. "Closeness" is defined in terms of a distance metric, such as the Euclidean distance [5].

Our dataset is composed of 10 Attributes, i.e. Thai1, Mathematics1, Science1, Social Study1, English1, Thai2, Mathematics2, Science2, Social Study2, and English2 (when the number " 1 " in the last position of subject name identifies that the subject was in the examination for Grade 9 students and the number " 2 " was the one for Grade 12 students). Of these 10 attributes, we divided into 2 groups - input attributes, which are Thai1, Mathematics1, Science1, Social Study1, and English1, and class attributes, which are Thai2, Mathematics2, Science2, Social Study2, and English2. We used all 5 input attributes to build the classification model for each class attribute, using the 3 algorithms as mentioned above, and compare their performances. All attributes, both input and class attributes, was discretized into 4 classes, i.e. $\operatorname{High}(\mathrm{H})$, Medium-High(M-H), Medium-Low(M-L), and Low(L).

The classification results showed that all algorithms performed at the same high level of accuracy. But only Naïve Bayes gave all 4 predicted classes, while the other two gave 1 and 2 classes in some cases. Therefore, the preferred algorithm for our dataset is Naïve Bayes [6].

\section{B. Finding the Relevance between Each Learning Plan and Its Emphatic Subjects}

In this step, we find the relevance between each learning plan and its emphatic subjects by reviewing each learning plan curriculum of 42 schools. Then we calculate the average and standard deviation of studying time of each main subject, mentioned above, for each learning plan. After that, we conclude the emphatic subjects of each learning plan, as shown in Table I.

TABLE I: ThE EMPHATIC SUBJECTS OF EACH LEARNING PlaN

\begin{tabular}{ll} 
Learning Plan & The Emphatic Subjects \\
\hline Science-Math Plan & Science, and Mathematics \\
Arts-Math Plan & English, and Mathematics \\
Language-Arts Plan & English \\
Social-Arts Plan & Social Study, English, and Thai \\
General Arts Plan & Social Study, and English \\
\hline \hline
\end{tabular}

\section{Finding the Relevance between Students' MI and Suitable Learning Plan}

In this step, we find the relevance between students' MI and suitable learning plan by reviewing documents and research about multiple intelligence [7]-[21]. The relevance can be shown as Table II.

TABLE II: THE RELEVANCE BETWEen STUdENTS' MI AND SUITABLE LEARNING PLAN

\begin{tabular}{|c|c|}
\hline Multiple Intelligence & Suitable Learning Plan \\
\hline Verbal-linguistic & Language-Arts Plan \\
\hline Logical-mathematical & $\begin{array}{l}\text { Science-Math Plan } \\
\text { Arts-Math Plan }\end{array}$ \\
\hline Spatial-visual & $\begin{array}{l}\text { Science-Math Plan } \\
\text { General Arts Plan } \\
\text { Social-Arts Plan }\end{array}$ \\
\hline Bodily-kinesthetic & $\begin{array}{l}\text { Science-Math Plan } \\
\text { General Arts Plan } \\
\text { Social-Arts Plan }\end{array}$ \\
\hline Musical & $\begin{array}{l}\text { Language-Arts Plan } \\
\text { General Art Plan }\end{array}$ \\
\hline & Language-Arts Plan \\
\hline Interpersonal & $\begin{array}{l}\text { General Arts Plan } \\
\text { Social-Arts Plan }\end{array}$ \\
\hline Intrapersonal & $\begin{array}{l}\text { Language-Arts Plan } \\
\text { General Arts Plan } \\
\text { Social-Arts Plan }\end{array}$ \\
\hline Naturalist & Science-Math Plan \\
\hline
\end{tabular}

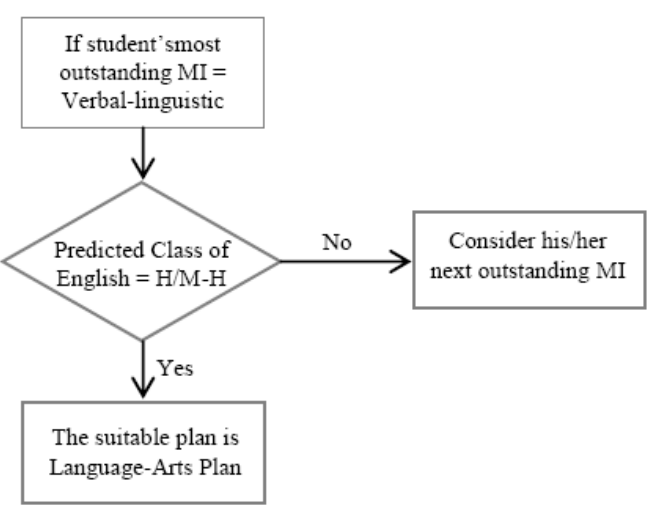

Fig. 1. Model for verbal-linguistic intelligence. 


\section{Synthesizing the Model}

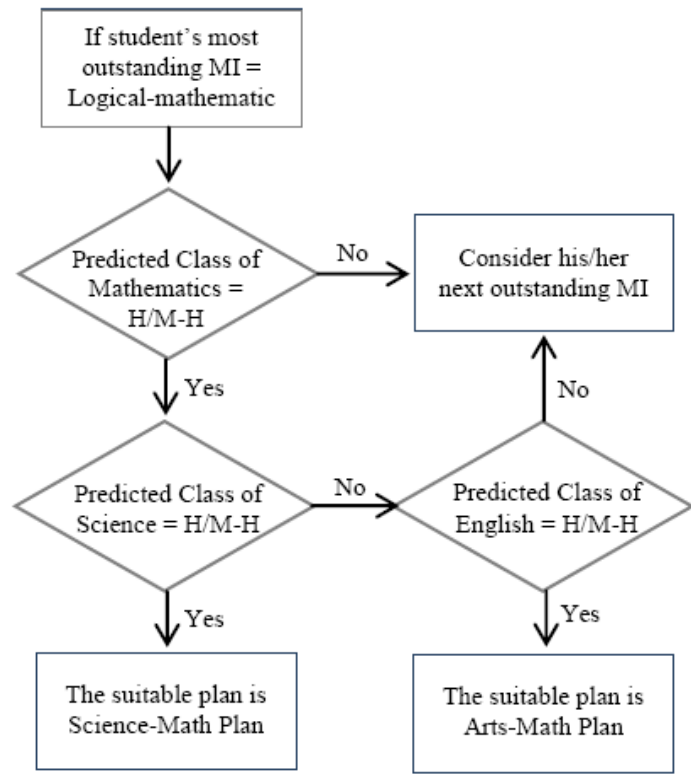

Fig. 2. Model for logical-mathematical intelligence.

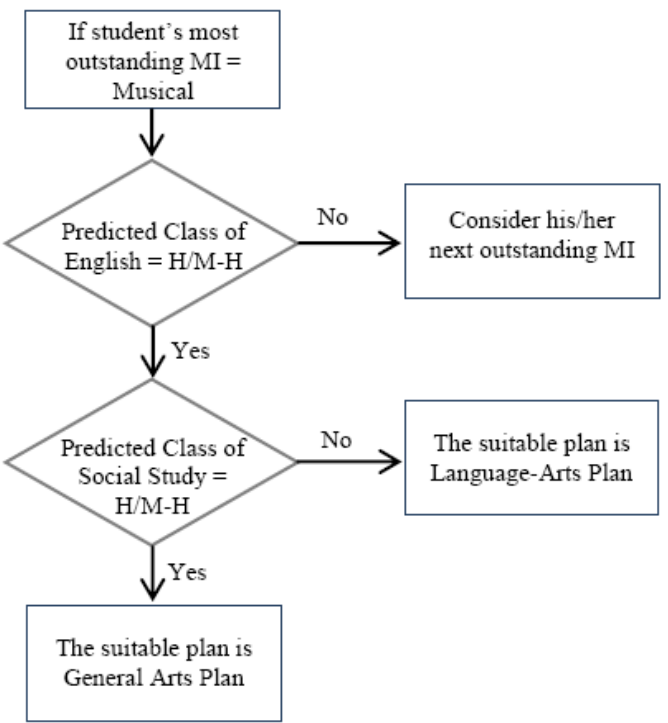

Fig. 3. Model for musical intelligence.

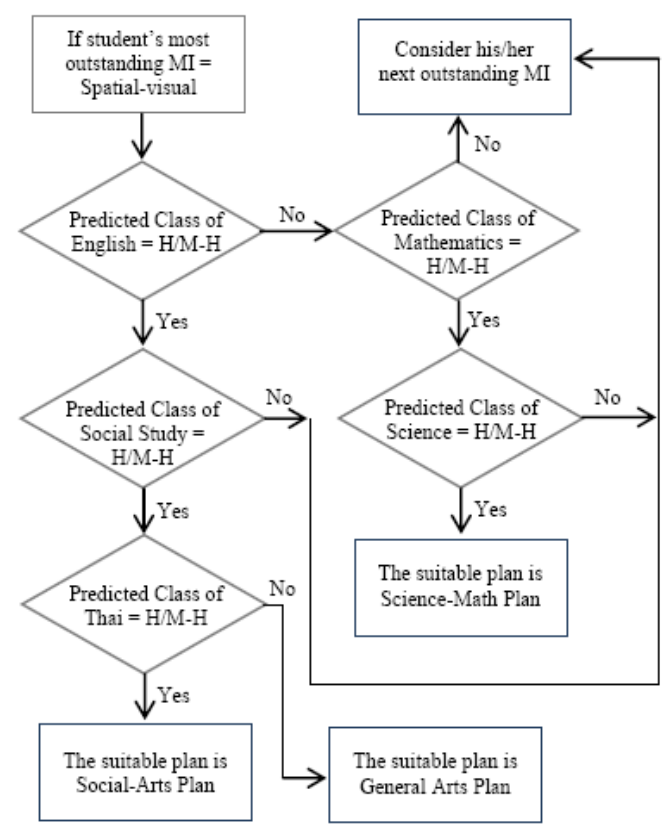

Fig. 4. Model for spatial-visual intelligence.

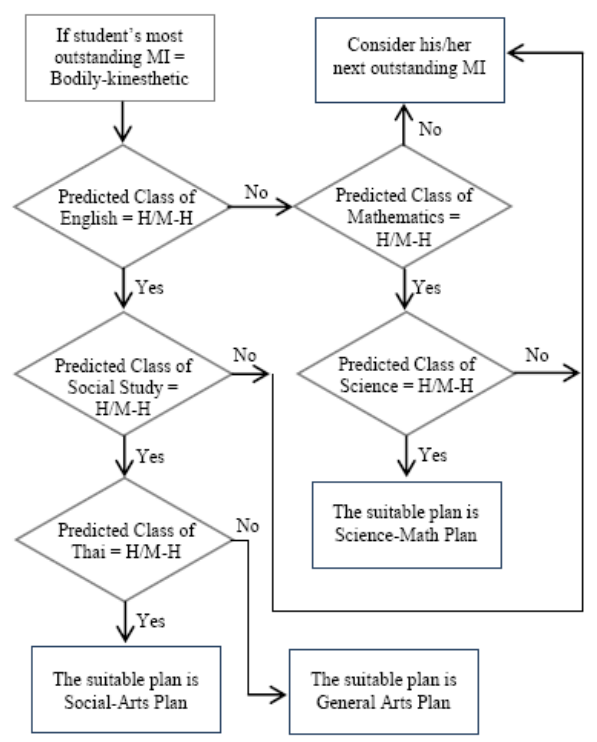

Fig. 5. Model for bodily-kinesthetic intelligence.

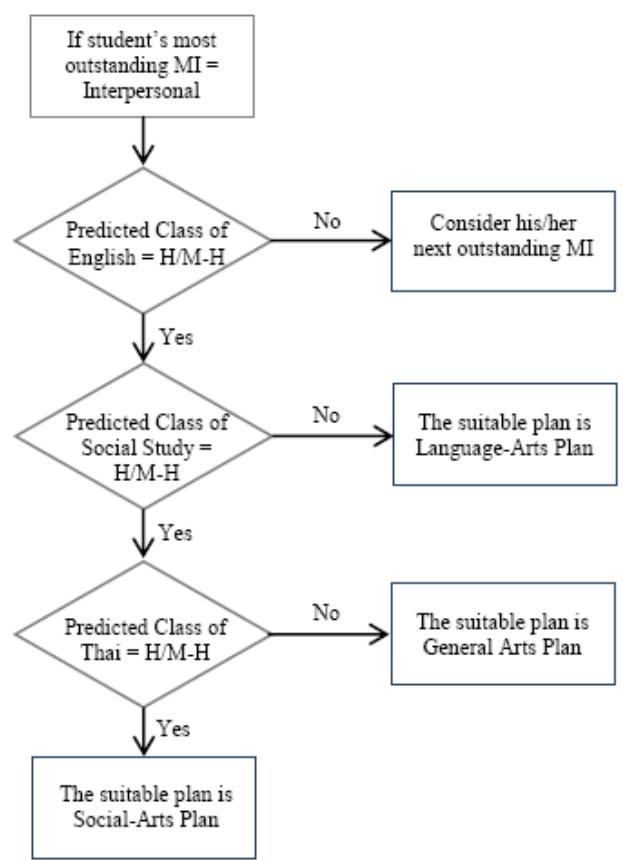

Fig. 6. Model for interpersonal intelligence.

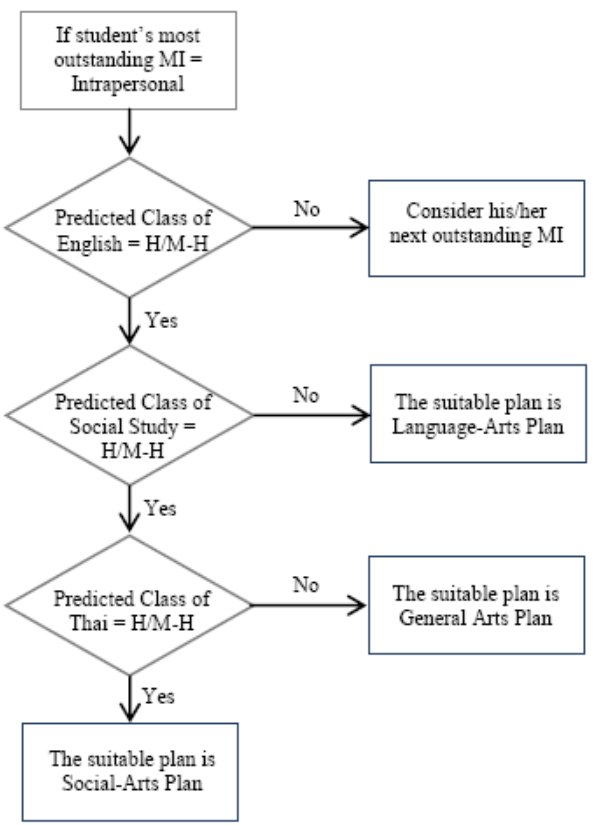

Fig. 7. Model for intrapersonal intelligence. 


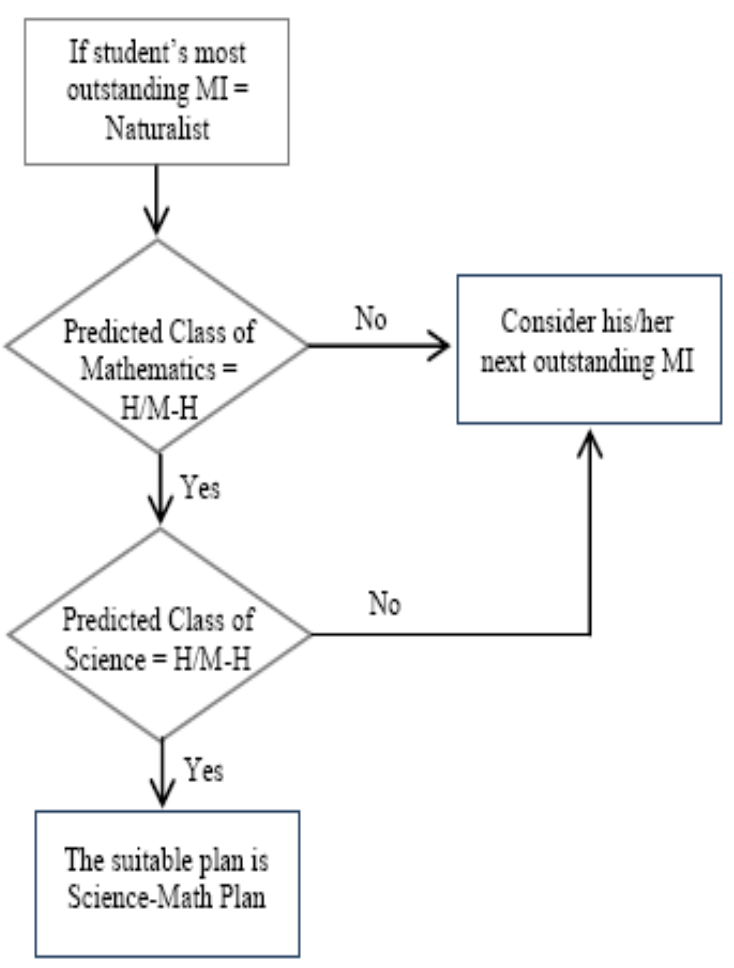

Fig. 8. Model for naturalist intelligence.

In this step, we synthesize the model by assembling the outcomes from the previous three steps. The synthesis model is divided into 8 parts according to each MI, as shown in Fig. 1-Fig. 8.

\section{THE PROPOSED MODEL}

The proposed model is divided into 3 parts - Input, Process, and Output of the model, as shown follows;

\section{A. The Model Input}

Students who use this model have to provide 2 parts of information into the model. Firstly, they have to fill in their Grade 9 O-NET scores of 5 subjects, i.e. Thai, Mathematics, Science, Social Study, and English. Secondly, they have to answer the MI questionnaire, in order to give information about their outstanding MI(s).

\section{B. The Model Process}

After got the mentioned input data, the model will perform the process, which is divided into two steps, i.e. using classification technic of data mining to predict Grade 12 O-NET scores from Grade 9 O-NET scores of students, and using the predicted scores together with students' MI to suggest appropriate learning plan(s) to students.

\section{The Model Output}

After finishing the process, the model gives a list of appropriated learning plan(s) to the students.

\section{CONCLUSIONS}

In this research, we proposed a model of decision support system for choosing high school learning plan using students' O-NET scores and multiple intelligence. In the near future, we will implement this model inform of web service, in order to provide a new tool for the student counselors to use for guiding students to choose their appropriate learning plan.

\section{REFERENCES}

[1] The National Institute of Educational Testing Service (Public Organization). (2014). Exam Information. [Online]. Available: http://www.niets.or.th

[2] M. H. Dunham, Data Mining: Introductory and Advanced Topics, Boston: Pearson Education Inc., 2003.

[3] American Institute for Learning and Human Development. (2014). Multiple Intelligence. [Online]. Available: http://www.institute4learning.com/multiple_intelligences.php

[4] Northern Illinois University, Faculty of Development and Instructional Design Center. (2014). Howard Gardner's Theory of Multiple Intelligences. [Online]. Available: http://www.niu.edu/facdev/resources/guide/learning/howard_gardner _theory_multiple_intelligences.pdf

[5] Rapidminer. (2014). Rapidminer operator reference. [Online] Available: http://rapidminer.com/documentation/

[6] T. Sintanakul and C. Sanrach, "A comparison of classification algorithms on the O-NET scores," presented at the 2nd International Conference on Technical Education, 2014.

[7] H. Gardner, Multiple Intelligence: The Theory in Practice, New York: Basic Books, 1993.

[8] T. Sirirattanarekha. (2014). Multiple Intelligence Theory. [Online]. Available: http://portal.edu.chula.ac.th/mimpimjai/

[9] S. Thessana. (2014). Multiple Intelligence: The Different Learning Ways. [Online]. Available: http://www.ndr.ac.th/mi/mi_selftest $1 . h t m$

[10] Sombunwit School. (2014). 8 Intelligences. [Online]. Available: http://sombunwit.ac.th/academic/multiple-intelligences/

[11] S. Punyaphuek. (2014). A New Dimension of Genius: Multiple Intelligence. [Online]. Available: http://www.stou.ac.th/study/sumrit/

[12] Thewphaingarm School. (2014). Multiple Intelligence. [Online]. Available:

http://www.thewphaingarm.ac.th/ArticleList.aspx?type=MultipleIntell igences

[13] S. Chaichomchuen, "A development of adaptive online learning activities system based on knowledge management process for FTE students," Ph.D. dissertation, Department of Computer Education, King Mongkut's University of Technology North Bangkok, Bangkok, Thailand, 2010.

[14] Y. Saisranoi, "A development of multiple intelligences test for upper secondary education level students of Nakhon Ratchasima Educational Service Area Office," M.Ed. thesis, Department of Educational Psychology, Nakhon Ratchasima Rajabhat University, Nakhon Ratchasima, Thailand, 2010.

[15] P. Ounwattana and K. Moungchoo, "The relationship among the multiple intelligences and English reading ability of first year students in Rajamangala University of Technology PhraNakhon," Rajamangala University of Technology Phra Nakhon, Bangkok, Thailand, 2008.

[16] W. Waramit, "The relationships between factors of multiple intelligence, achievement and learning achievement as well as attitude toward English of Mattayomsuksa 3 students in educational opportunity extension school under the office of Mahasarakham provincial primary education," M.Ed. thesis, Department of Educational Measurement, Mahasarakham University, Mahasarakham, Thailand, 2003.

[17] P. Kanuman, "The relationships between multiple intelligence and attitude toward physics and physics achievement of Mattayomsuksa 6 in Mahasarakham Province," M.Ed. thesis, Department of Educational Research, Mahasarakham University, Mahasarakham, Thailand, 2005

[18] T. Srisangkaew, "The relations between multiple intelligence ability and the learning achievement of the students of primary grade 6 under Songkhla Metropolitan Municipality, Songkhla Province," M.Ed thesis, Department of Educational Measurement, Thaksin University, Songkhla, Thailand, 2007.

[19] K. Sintuwong et al., "The multiple intelligences of Khon Kaen University students," Khon Kaen University, Khon Kaen, Thailand, 2002.

[20] P. Saengngam, "A study of relationships between multiple intelligences and vocational interest of Mattayomsuksa V Students,' M.Ed. thesis, Department of Educational Measurement, Srinakarinwirot University, Bangkok, Thailand, 2004.

[21] N. Paowpan, L. Wattanaboot, S. Satitanun, and S. Sornsena, “A study on learning English vocabulary through a visual memory model based on theory of multiple intelligence for vocational diploma students, 
teerapada technology school, Roi-Et Province," Rajabhat Maha Sarakham University Journal, vol. 5, no. 3, pp. 57-66, 2011.

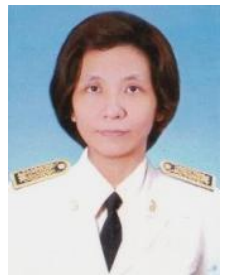

Thanrat Sintanakul received the MS degree in information technology from King Mongkut's University of Technology North Bangkok (KMUTNB), Bangkok, Thailand in 2003. Currently, she is a computer education $\mathrm{PhD}$ candidate at KMUTNB. Her research interests include data mining and applying technology for learning and teaching. Currently, she is with the Department of Computer Education, Faculty of Technical Education, King Mongkut's University of Technology North Bangkok, Bangkok, Thailand.

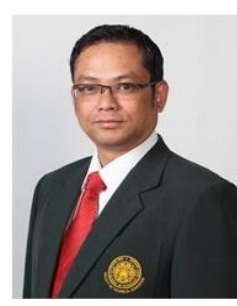

Charun Sanrach received the $\mathrm{Ph} . \mathrm{D}$. degree in diplôme de docteur (informatique) INPL, France. His research interests include applying artificial intelligence in computer education, applying technology for learning and teaching, problem-based learning, project-based learning, and constructivist. Currently, he is with the Department of Computer

Education, Faculty of Technical Education, King Bangkok, Bangkok, Thailand.
Mongkut's University of Technology North 